\title{
Review Article \\ Role of Endothelial to Mesenchymal Transition in the Pathogenesis of the Vascular Alterations in Systemic Sclerosis
}

\author{
Sergio A. Jimenez ${ }^{1,2}$ \\ ${ }^{1}$ Jefferson Institute of Molecular Medicine, Philadelphia, PA 19107, USA \\ ${ }^{2}$ Scleroderma Center, Thomas Jefferson University, Philadelphia, PA 19107, USA \\ Correspondence should be addressed to Sergio A. Jimenez; sergio.jimenez@jefferson.edu
}

Received 14 July 2013; Accepted 9 August 2013

Academic Editors: S. Bombardieri, H. Ihn, and T. Yamamoto

Copyright ( $\odot 2013$ Sergio A. Jimenez. This is an open access article distributed under the Creative Commons Attribution License, which permits unrestricted use, distribution, and reproduction in any medium, provided the original work is properly cited.

\begin{abstract}
The pathogenesis of Systemic Sclerosis (SSc) is extremely complex, and despite extensive studies, the exact mechanisms involved are not well understood. Numerous recent studies of early events in SSc pathogenesis have suggested that unknown etiologic factors in a genetically receptive host trigger structural and functional microvascular endothelial cell abnormalities. These alterations result in the attraction, transmigration, and accumulation of immune and inflammatory cells in the perivascular tissues, which in turn induce the phenotypic conversion of endothelial cells and quiescent fibroblasts into activated myofibroblasts, a process known as endothelial to mesenchymal transition or EndoMT. The activated myofibroblasts are the effector cells responsible for the severe and frequently progressive fibrotic process and the fibroproliferative vasculopathy that are the hallmarks of SSc. Thus, according to this hypothesis the endothelial and vascular alterations, which include the phenotypic conversion of endothelial cells into activated myofibroblasts, play a crucial role in the development of the progressive fibrotic process affecting skin and multiple internal organs. The role of endothelial cell and vascular alterations, the potential contribution of endothelial to mesenchymal cell transition in the pathogenesis of the tissue fibrosis, and fibroproliferative vasculopathy in SSc will be reviewed here.
\end{abstract}

\section{Introduction}

Scleroderma or Systemic Sclerosis (SSc) is an autoimmune disease of unknown etiology characterized by progressive fibrosis of skin and multiple internal organs and prominent and often severe alterations in the microvasculature [1]. Although SSc is the third most common systemic inflammatory autoimmune disease and has the highest case-specific mortality among this group of idiopathic disorders, there is currently no effective disease-modifying therapy for SSc. Therefore, there is an urgent unmet need for the development of effective disease-modifying therapies to improve the devastating health consequences and high mortality caused by the disease. The cells responsible for the severe fibroproliferative process in SSc are activated myofibroblasts, a unique population of mesenchymal cells displaying unique biological functions including increased production of fibrillar type 1 and type 111 collagens, initiation of expression of $\alpha$-smooth muscle actin $(\alpha$-SMA), a molecular marker of activated myofibroblasts, and reduction in the expression of genes encoding extracellular matrix (ECM)-degradative enzymes. The accumulation of myofibroblasts in affected tissues and the persistence of their elevated biosynthetic functions are crucial determinants of the extent and rate of progression of the fibrotic process in SSc, and of its clinical course, response to therapy, prognosis, and overall mortality. The origins of the myofibroblasts responsible for the exaggerated and uncontrolled production of collagen and other ECM proteins in SSc have not been completely elucidated. Extensive research studies have shown that these cells originate from several sources, including expansion of resident tissue fibroblasts and migration and tissue accumulation of bone marrow-derived circulating fibrocytes, or from epithelial cells which have undergone epithelial to mesenchymal transition (EMT). More recent studies, however, have demonstrated that endothelial cells are also capable of undergoing endothelial to mesenchymal transition (EndoMT) and that this transition might be an important source of the mesenchymal 
cells participating in the fibroproliferative vasculopathy and the fibrotic process in SSc. Thus, this novel mechanism of generation of activated myofibroblasts may represent an important and currently unexplored target for the development of disease-modifying therapeutic interventions for this currently incurable disease.

\section{SSc Pathogenesis: Overview}

The pathogenesis of SSc is extremely complex, and despite numerous studies that examined several aspects of its intricate picture, the exact mechanisms involved are not well understood. However, it is apparent that the clinical and pathologic manifestations of the disease are the result of three distinct processes: (1) fibroproliferative vascular lesions of small arteries and arterioles, (2) excessive and often progressive deposition of collagen and other ECM macromolecules in skin and various internal organs, and (3) alterations of humoral and cellular immunity characterized by innate immunity alterations, involvement of macrophages and Tand B-lymphocytes, and the production of numerous diseasespecific autoantibodies [2-4]. It has not been established which of these processes is of primary importance or how they are temporally related during the development and progression of the disease. However, numerous recent studies have clarified some of the early events in SSc pathogenesis [5-11]. A current hypothesis for SSc pathogenesis posits that there is a sequence of pathogenetic events initiated by unknown etiologic factors in a genetically receptive host which trigger microvascular injury characterized by structural and functional endothelial cell abnormalities. The endothelial cell abnormalities result in the increased production and release of numerous and potent mediators including cytokines, chemokines, polypeptide growth factors, and various other substances such as nitric oxide, prostaglandins, reactive oxygen species (ROS), and thrombogenic and procoagulant activities or in the reduction of important compounds such as prostacyclin. The endothelial cell dysfunction triggers the chemokine and cytokine-mediated attraction of specific inflammatory cellular elements from the bloodstream and bone marrow and their transmigration into the surrounding tissues. These events lead to the establishment of a chronic inflammatory process with participation of macrophages and T- and B-lymphocytes, with further production and secretion of cytokines and growth factors that induce the tissue accumulation of activated myofibroblasts, the effector cells responsible for the fibrotic process [1214]. This sequence of events, diagrammatically illustrated in Figure 1, results in the development of a severe and often progressive fibroproliferative vasculopathy and in the exaggerated and widespread accumulation of fibrotic tissue in the skin and multiple internal organs, which are the most salient characteristics of the disease.

The purpose of this review is to discuss recent studies that have substantially advanced the current understanding of SSc pathogenesis regarding the endothelial cell and vascular abnormalities and the role of endothelial to mesenchymal transition (EndoMT) in the pathogenesis of this currently incurable disease. However, the genetic, innate, and acquired immunological abnormalities and the cytokine, chemokine, and growth factor abnormalities, all of which play an extremely important role in SSc pathogenesis, will not be reviewed here owing to the availability of numerous outstanding reviews about these topics that have been recently published [15-22].

\section{Vascular Abnormalities in SSc}

Vascular dysfunction is one of the earliest and most noticeable manifestations of SSc as indicated by the occurrence of Raynaud phenomenon, nailfold capillary microvascular alterations, and digital ulcers almost universally in SSc patients often preceding the appearance of clinical evidence of tissue fibrosis [23, 24]. Furthermore, there is a remarkable microvascular fibroproliferative vasculopathy present in essentially all SSc affected organs that is responsible for the most important symptoms and clinical manifestations of SSc and often leads to serious and even fatal complications. Although the effects of vascular abnormalities and dysfunction in patients with SSc are most dramatic when they involve the pulmonary and renal arterioles, causing renal crisis $[25,26]$ and pulmonary artery hypertension $[27-$ 29], respectively, there are numerous other important clinical manifestations of the disease that are caused or mediated by the prominent fibroproliferative vasculopathy. These include capillary rarefaction and capillary loop dilation in the nailfold capillaries $[30,31]$, cutaneous and mucosal telangiectasias [32-34], erectile dysfunction resulting from alterations in penile blood flow [35-37], and cardiac dysfunction including nonartherosclerotic myocardial infarcts $[38,39]$, gastric antral vascular ectasia [40-42], central retinal artery occlusion $[43,44]$, and involvement of larger vessels $[45,46]$. Histopathologically, the affected vessels display marked narrowing or even complete occlusion of the vessel lumen with remarkable accumulation of mesenchymal cells and fibrous tissue in the subendothelial compartment and associated endothelial cell abnormalities, which include swelling and apoptotic changes, as well as thickening of the basement membrane. Occasionally, endothelial cell detachment and intravascular platelet thrombi are found. On transmission, electron microscopy universal morphological changes of endothelial cells and basement membrane duplication and lamellation are characteristic alterations. The histopathological changes in the microvasculature of several affected organs are illustrated in Figure 2.

\section{Mechanisms of Vascular and Endothelial Cell Injury in SSc}

The initial events responsible for the vascular and endothelial cell injury and their subsequent activation are not known although numerous putative etiologic factors have been suggested. Some of these include exogenous chemical substances, vasculotropic viral pathogens, antiendothelial cell antibodies, cellular products from inflammatory cells, tissue hypoxia, or ROS generated during episodes of ischemia/reperfusion [8-10, 47-52]. The injured/activated 


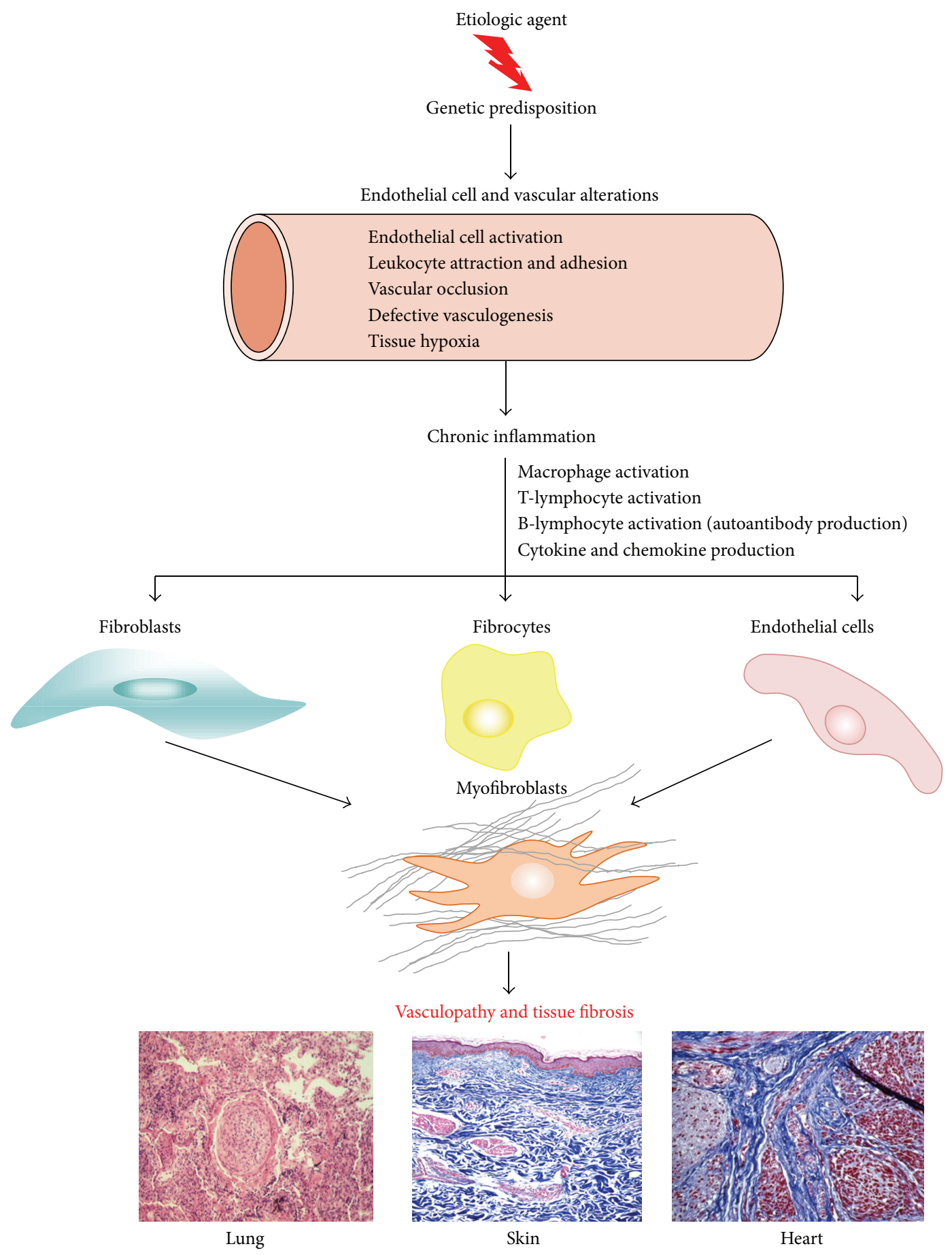

FIGURE 1: Overall scheme illustrating a current understanding of SSc pathogenesis. Hypothetical sequence of events involved in tissue fibrosis and fibroproliferative vasculopathy in SSc. An unknown causative agent induces activation of immune and inflammatory cells in genetically predisposed hosts resulting in chronic inflammation. Activated inflammatory and immune cells secrete cytokines, chemokines, and growth factors which cause fibroblast activation, differentiation of endothelial and epithelial cells into myofibroblasts, and recruitment of fibrocytes from the bone marrow and the peripheral blood circulation. The activated myofibroblasts produce exaggerated amounts of ECM resulting in tissue fibrosis.

endothelial cells may undergo apoptosis or may detach from the vascular endothelium, leaving a denuded vascular lumen which triggers the release of endothelial cell precursors from the bone marrow in attempts to repair the endothelial lining defects. Supporting this notion are the observations of increased numbers of circulating endothelial cells and endothelial cell precursors in SSc patients [53-55]. The activation of endothelial cells also induces the expression of cell adhesion molecules such as ICAM, VCAM-1, and Eselectin $[56,57]$. The induced expression of cell adhesion 
Fibroproliferative vasculopathy in SSc


Pulmonary arterioles



Renal arterioles

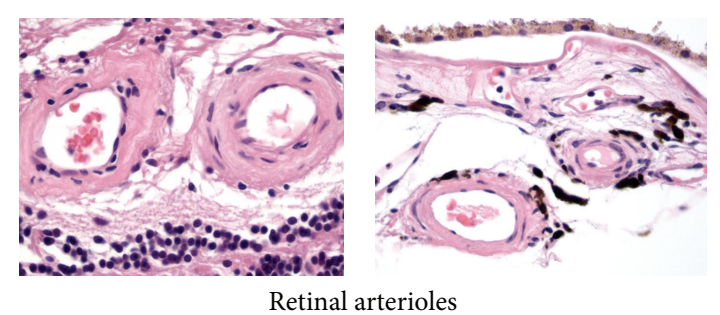

Retinal arterioles

FIGURE 2: Histopathology of fibroproliferative vasculopathy in small vessels of various affected organs. Histopathology of microvascular arterioles from SSc lung, kidney, and retinal vessels displaying prominent endothelial fibroproliferative alterations causing severe narrowing of vessel lumen and thickening of vessel walls.

molecules by the endothelial cells leads to recruitment and activation of chronic inflammatory cells, including T- and B-lymphocytes and profibrotic macrophage populations and their accumulation in the perivascular tissue and in the interstitium of parenchymal organs. The activated chronic inflammatory cells are responsible for the increased production of transforming growth factor- $\beta$ (TGF- $\beta$ ), connective tissue growth factor (CTGF), and other profibrotic polypeptide growth factors which together with the mediators released by the endothelial cells, such as endothelin-1, induce subsequent pathogenetic events leading to the severe tissue fibrosis and fibroproliferative vasculopathy characteristic of the disease [1-11]. Besides the endothelial cell abnormalities, other vascular alterations include increased proliferation of smooth muscle cells in the medial layer of affected vessels, marked accumulation of fibrotic tissue in the subendothelial compartment, and initiation of platelet aggregation and intravascular thrombosis, eventually causing microvascular occlusion $[58,59]$. These multiple events result in tissue hypoxia which can cause activation of hypoxia-dependent profibrogenic processes, including further increases in production of TGF- $\beta$ and interstitial collagens as well as other ECM macromolecules [60, 61]. In addition to the structural vascular changes described above, there are also functional vascular alterations which include a reduction in endothelium dependent vasodilator molecules and dysfunction of the neurovascular and neuroendothelial control of vasodilation [62-65], as well as a relative deficiency of vasodilator molecules such as prostacyclin and nitric oxide.

The injured or cytokine/growth factor-activated endothelial cells also produce increased amounts of the potent profibrotic and vasoconstrictor polypeptide, endothelin-1 $[66,67]$, and numerous other vasoactive and prothrombogenic compounds that are capable of directly stimulating various target cells such as vascular smooth muscle cells and fibroblasts [8$10,66,67]$. The important role of endothelin-1 in the development of SSc-associated tissue fibrosis and fibroproliferative vasculopathy has received increasing attention recently. Indeed, elevated levels of endothelin-1 have been found in plasma and bronchoalveolar lavage of SSc patients [68-70] and correlate with clinical parameters and subsets of the disease [71,72]. Numerous studies have demonstrated that endothelin-1 is a potent inducer of proliferation and ECM production by fibroblastic cells [73-76]. The exaggerated vasoconstrictor response to the increased endothelin levels causes vascular hypoxia and further endothelial injury, thus establishing and maintaining a vicious cycle of endothelial injury and fibrosis. The chronic inflammatory cells accumulated in the perivascular environment also participate in the maintenance of a powerful profibrotic cycle since the numerous cytokines, chemokines, and growth factors they produce can in turn induce further activation of the endothelial cells and their production of profibrotic mediators [67]. The mutual interaction between inflammatory and endothelial cells has been validated by a recent study describing the upregulation of endothelin- 1 and TGF- $\beta$ in human microvascular endothelial cells induced by interferon- $\gamma$, one of the potent cytokines released by the infiltrating inflammatory cells [77]. Additional alterations which contribute to the severe vascular dysfunction and rarefaction in SSc are the result of disordered angiogenesis [78-84] and impaired differentiation of bone marrow stem cells into endothelial cells [85]. 


\section{Endothelial to Mesenchymal Transition (EndoMT) in the Pathogenesis of SSc}

One of the most characteristic histopathologic alterations in SSc is a severe fibroproliferative vasculopathy affecting the microvasculature as well as some larger vessels [86]. The proliferative vasculopathy of SSc has two distinct components. The first one is a marked proliferation of smooth muscle cells in the media of medium size and small size arterioles, a process which plays a crucial role in SScassociated pulmonary hypertension. The second component is most prominent in the small arterioles of parenchymal organs, such as the lungs and kidneys, and is characterized by the subendothelial accumulation of activated fibroblasts or myofibroblasts and the production of abundant fibrotic tissue. The origin of mesenchymal cells responsible for the fibrotic microvascular occlusion in SSc is not known, but recent studies have suggested that at least some of these cells may result from EndoMT, that is, the transdifferentiation of endothelial cells into subintimal fibroblasts induced by locally-secreted cytokines and growth factors. During EndoMT, endothelial cells lose their specific endothelial cell markers, such as vascular endothelial cadherin (VE cadherin) and von Willebrand factor, and acquire a mesenchymal or myofibroblastic phenotype initiating expression of $\alpha$-SMA, vimentin, and type I collagen. In addition, these cells become motile and are capable of migrating into surrounding tissues. EndoMT has been described as an important process during cardiac valve and pulmonary artery embryonic development [87-89]. More recently, EndoMT has emerged as a possible mechanism in the pathogenesis of tissue fibrosis in various diseases, including diabetic nephropathy, cardiac fibrosis, intestinal fibrosis, portal hypertension, and pulmonary hypertension [90-100]. Although there is some experimental evidence supporting the participation of EndoMT in SSc, further studies will be required to conclusively demonstrate that EndoMT plays a role in the pathogenesis of SSc-associated fibroproliferative vasculopathy and progressive tissue fibrosis. A firm demonstration of the occurrence of EndoMT in SSc and a further understanding of the molecular mechanisms involved may lead to the pharmacologic modulation or abrogation of this pathway in SSc.

\section{Molecular Mechanisms of EndoMT}

The molecular mechanisms involved in the EndoMT process have not been fully elucidated, and despite the remarkable importance of this process to normal development and to various pathologic conditions including SSc, only a few studies have examined the molecular changes and the regulatory events occurring in endothelial cells during their transdifferentiation into mesenchymal cells or myofibroblasts. However, substantial recent evidence has accumulated demonstrating the crucial role of TGF- $\beta$ signaling [101-104] in the initiation of EndoMT during normal development as well as in various diseases.
6.1. Role of TGF- $\beta$ in EndoMT. TGF- $\beta$ is a pleiotropic growth factor involved in numerous physiologic and pathologic processes including embryogenesis, cellular development and differentiation, immunologic system development, inflammatory response functions, and wound repair [105-107]. TGF- $\beta$ plays a key role in the pathogenesis of fibrotic diseases by stimulating the production of various collagens and other ECM components by mesenchymal cells and by inhibiting the expression of various relevant metalloproteinases [103, 104, 108-114]. Although the precise mechanisms mediating the potent profibrotic effects of TGF- $\beta$ have not been completely elucidated, it appears that TGF- $\beta$ may cause the establishment of an autocrine signaling cascade capable of continuous activation of profibrotic gene expression in the target cells [115]. However, extensive studies have shown that besides causing a potent stimulation of the expression of genes participating in the exaggerated production and accumulation of ECM, TGF- $\beta$ is also involved in the generation of myofibroblasts through EndoMT [101-104, 116-121]. Indeed, studies in experimentally induced cardiac hypertrophy showed that TGF- $\beta$ was a crucial mediator causing endothelial cells to undergo EndoMT [96]. Although the detailed molecular events and the intracellular cascades activated by TGF- $\beta$ that result in the remarkable phenotypic change of endothelial cells to mesenchymal cells have not been entirely elucidated, recent studies in cultured human cutaneous microvascular endothelial cells [103], primary cultures of murine pulmonary endothelial cells [116], and cultured pancreatic microvascular endothelial cells [121] demonstrated that both Smaddependent and Smad-independent pathways are involved. The intracellular signaling pathways that are likely to be involved in EndoMT induction by TGF- $\beta$ are illustrated in Figure 3.

Given the crucial role of TGF- $\beta$ in the development of tissue fibrosis and its participation in the pathogenesis of numerous fibrotic diseases, we recently examined the mechanisms involved in the induction of EndoMT by this pleotropic growth factor and studied the intracellular transduction pathways involved in this process employing primary pulmonary endothelial cells in culture [116]. In our study, we examined the transdifferentiation of murine pulmonary endothelial cells into mesenchymal cells in vitro and the signaling pathways involved in this process and made the following observations: (1) primary murine pulmonary endothelial cells undergo EndoMT in response to TGF- $\beta$ with initiation of expression of $\alpha$-SMA, assembly of typical intracellular $\alpha$-SMA stress fibers, and loss of VE-cadherin in vitro; (2) TGF- $\beta$ induction of EndoMT was associated with a strong upregulation in the expression of the transcriptional repressor Snail-1 indicating that Snail-1 is directly involved in TGF- $\beta$-induced $\alpha$-SMA expression; and (3) induction of $\alpha$-SMA expression in pulmonary endothelial cells was mediated by the c-Abl kinase and by protein kinase c$\delta(\mathrm{PKC}-\delta)$, as specific inhibition of their kinase activity with imatinib mesylate and rottlerin, respectively, or by knockdown of their corresponding transcripts with specific siRNA abrogated the marked increase in TGF- $\beta$ induced $\alpha$-SMA and Snail-1 expression and protein levels. These studies collectively showed that these effects are mediated 


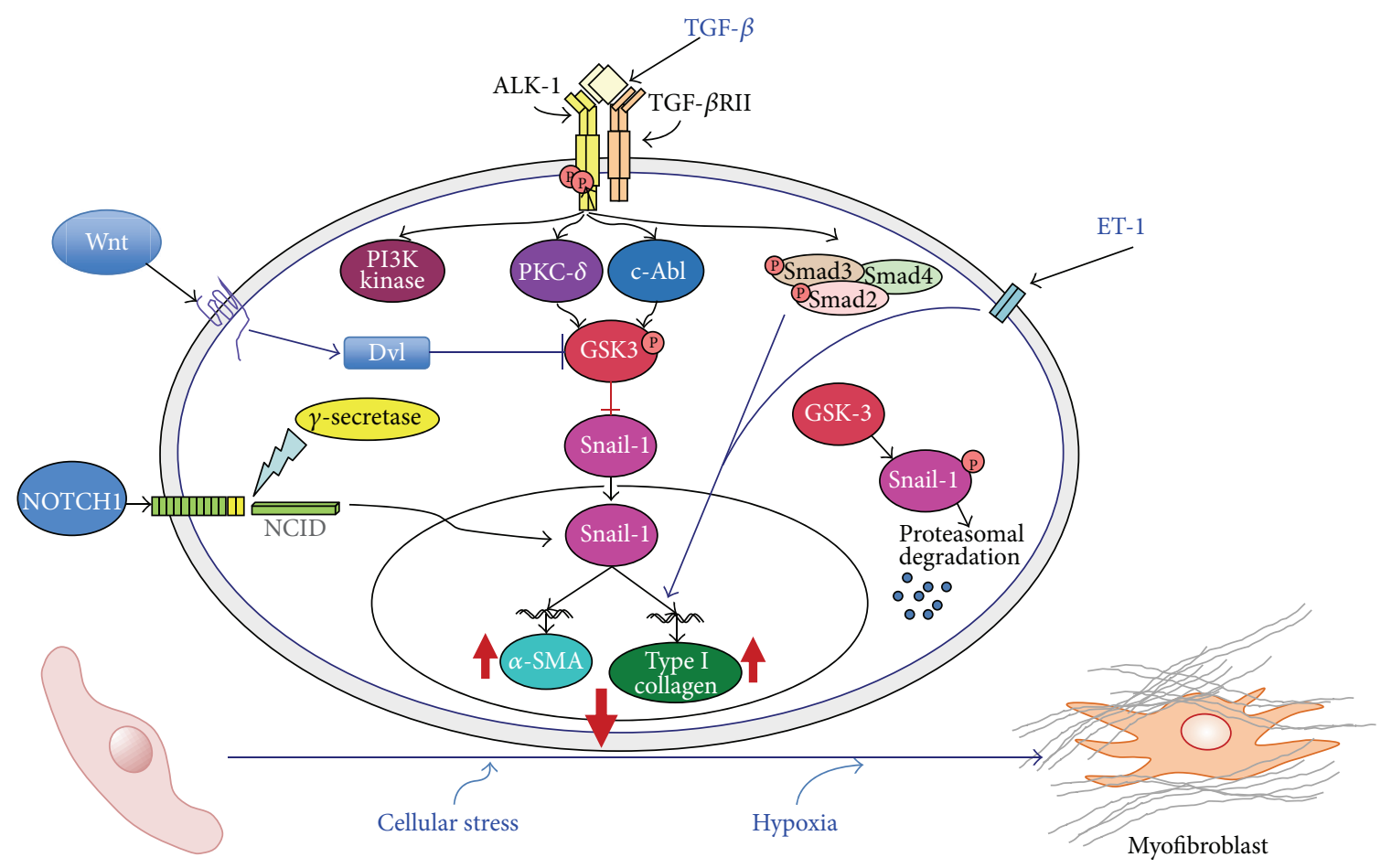

Endothelial cell

FIGURE 3: Signaling pathways involved in EndoMT. The diagram shows the numerous putative pathways that may participate in the EndoMT process and may be involved in SSc pathogenesis. One central pathway initiated following ligand-binding activation of the Smad-independent TGF- $\beta$ pathway causes phosphorylation of GSK- $3 \beta$ mediated by PKC- $\delta$ and the c-Abl nonreceptor kinase. Phosphorylation of GSK-3 $\beta$ at serine 9 (ser9) causes its inhibition which then allows Snail-1 to enter the nucleus. Nuclear accumulation of Snail-1 results in marked stimulation of Snail-1 expression which then leads to acquisition of the myofibroblast phenotype with stimulation of $\alpha$-SMA. The inhibition of GSK-3 $\beta$ ser9 phosphorylation by specific inhibition of PKC- $\delta$ or c-Abl activity allows GSK- $3 \beta$ to phosphorylate Snail-1 targeting it for proteosomal degradation and thus effectively abolishes the acquisition of the myofibroblastic phenotype and the fibrotic response. Other pathways such as those involving ET-1, Wnt, NOTCH, hypoxia, and cellular stress responses may also participate although the molecular events have not been fully elucidated. Modified from Piera-Velazquez and Jimenez [101].

by the transcriptional repressor Snail-1 $[103,116]$. Snail-1 is a zinc-finger transcription factor that forms a complex with Smad3/Smad4. The active Smad3/Smad4/Snail-1 complex causes potent inhibition of the expression of E-cadherin by directly binding to specific sequences within the gene promoter and blocking its transcription. Besides inhibition of E-cadherin, Snail-1 induces numerous transcriptional events that lead to the expression of a mesenchymal-cell-specific phenotype. Snail-1 levels are regulated by complex phosphorylation events mediated by intracellular kinases including c-Abl kinase, PKC- $\delta$, PI3K, p38 MAP kinase and glycogen synthase kinase $3 \beta$ (GSK-3 $\beta$ ). The role of PKC- $\delta$ and c-Abl kinases has been demonstrated employing specific kinase inhibitors and/or specific knockdown with small interfering RNAs [116], whereas the role of PI3K, p38 MAPK and GSK$3 \beta$ was demonstrated employing specific inhibitors of the corresponding pathways [103]. Numerous studies have shown a crucial role of GSK-3 $\beta$ in the regulation of Snail-1 effects. GSK- $3 \beta$ phosphorylation results in its inactivation which in turn induces the nuclear accumulation of Snail-1 followed by a profound increase in the expression of its corresponding gene. In contrast, in the absence of GSK- $3 \beta$ phosphorylation, the GSK- $3 \beta$ kinase is active and induces the proteosomal degradation of Snail-1, thus abrogating the endothelial to mesenchymal cellular phenotypic conversion. The role of GSK-3 $\beta$ in the regulation of Snail-1 stability, and therefore, in the expression of its potent transcriptional effects is illustrated in Figure 3.

\subsection{Regulation of EndoMT by the Wnt and NOTCH Signaling} Pathways. Although not extensively studied in EndoMT, it has recently become apparent that several important regulatory pathways including the canonical Wnt pathway and the NOTCH pathway may also participate in the regulation of EndoMT as illustrated in Figure 3.

6.2.1. Wnt Signaling. The Wnt proteins comprise a large family of secreted glycoproteins with complex canonical and noncanonical intracellular signaling pathways that play crucial roles during embryonic development and organogenesis [122-124]. Wnt proteins and pathways have been recently implicated in the pathogenesis of numerous diseases, including SSc and other fibrotic diseases [125-129]. TGF- $\beta$ appears to be the major factor activating the canonical Wnt pathway $[130,131]$. This process is probably mediated by a decrease of Dickkopf-related protein 1 (Dkk-1), a potent Wnt pathway 
inhibitor, as indicated by the observations that the addition of recombinant Dkk-1 blocked the stimulatory effects of TGF- $\beta$ on the canonical Wnt pathway in fibroblasts $[132,133]$.

Although there is extensive published literature regarding the role of Wnt pathway activation in the phenotypic conversion of epithelial cells into mesenchymal cells, also known as EMT [134-137], the possibility that Wnt may participate in EndoMT is just beginning to be explored. Indeed, a recent study examined the role of Wnt7 and the Wnt7 antagonist Dkk-1 on EndoMT in primary aortic endothelial cells in culture and in transgenic mice with an endothelialspecific Wnt-7b deletion [138]. The results showed that Dkk-1 inhibition of the Wnt pathway enhanced EndoMT, whereas Wnt-7b expression preserved the endothelial cell phenotype.

6.2.2. NOTCH Signaling. The NOTCH proteins are members of the group of proteins collectively known as morphogens owing to their crucial roles in cell fate decisions during morphogenesis and embryonic development, particularly in relation to cardiovascular development and to regulation of central nervous system polarity and vertebrate segmentation $[139,140]$. However, involvement of NOTCH proteins in a broad spectrum of disorders is just becoming apparent [141-147]. The role of NOTCH signaling in EndoMT was first described by Noseda et al. [148], and it was suggested that the NOTCH pathway may be crucial for heart valve and cardiac cushion development and/or vascular smooth muscle differentiation. Numerous subsequent studies have confirmed and extended these observations and have examined the molecular mechanisms involved and the important interactions with the TGF- $\beta$ pathways [149-154]. Studies to examine the participation of $\mathrm{NOTCH}$ proteins in the EndoMT process in SSc have not been described, although the demonstration of activation of NOTCH signaling in affected SSc skin suggests that the NOTCH proteins may play a role in SSc pathogenesis and thus may represent a potential target for SSc disease modifying therapeutic approaches [155, $156]$.

6.3. Caveolin-1 Regulation of EndoMT. Another recently identified mechanism of regulation and fine tuning of TGF$\beta$ activity involves Caveolin-1 (Cav-1), the most important member of a family of proteins found in lipid rafts. Cav-1 plays an important role in TGF- $\beta$ signaling regulation owing to its participation in TGF- $\beta$ receptor (T $\beta \mathrm{R})$ internalization [157-159]. T $\beta$ Rs are internalized both by Cav-1-associated lipid rafts and by early endosome antigen 1 (EEA-1) nonlipid raft pathways. Non-lipid raft associated internalization increases TGF- $\beta$ signaling, whereas caveolin-associated internalization increases T $\beta \mathrm{R}$ degradation, thereby effectively decreasing or abolishing TGF- $\beta$ signaling [157]. The localization of the T $\beta$ Rs in the EEA-1 positive compartment is responsible for downstream Smad activation, whereas their localization in Cav-1 containing lipid rafts has been shown to cause subsequent receptor ubiquitination and rapid degradation and turnover $[158,159]$. Despite the important interactions between Cav-1 and TGF- $\beta$ and the numerous studies that supported the role of Cav-1 in the pathogenesis of SSc [160-164], the possibility that Cav-1 may participate in the regulation of EndoMT has not been explored in detail, although a recent study examined the contribution of Cav-1 to EndoMT employing Cav-1 knockout mice [165]. The results indicated that Cav-1 may be a crucial regulator of EndoMT in murine pulmonary endothelial cells. In these studies, it was shown that pulmonary endothelial cells isolated from Cav1 knockout mice displayed spontaneous EndoMT and that Cav-1 deficiency potentiated the EndoMT effect induced by TGF- $\beta[165]$.

6.4. Role of Other Growth Factors in EndoMT. The most severe clinical and pathologic manifestations of SSc are the result of a fibrotic process characterized by the excessive and often progressive deposition of collagen and other connective tissue macromolecules in skin and numerous internal organs. Numerous studies have shown that tissue fibrosis in SSc is the result of an upregulated expression of genes encoding collagen and other extracellular matrix proteins in affected organs. The exact mechanisms responsible for the establishment of the fibrotic process in SSc have not been precisely determined [2-6], although it has become very clear that several growth factors play a crucial role [166].

Besides TGF- $\beta$, the most important growth factor, involved in SSc tissue fibrosis and in EndoMT, other growth factors and profibrogenic molecules, including platelet derived growth factors [167], vascular endothelial growth factor [168], and insulin-derived growth factor [169], may also participate in EndoMT although their role in this process has not been studied to our knowledge. However, some studies that examined the role of other profibrotic growth factors have been described. One of the profibrotic polypeptides shown to participate in EndoMT is endothelin-1. One study showed that endothelial cell-derived endothelin-1 promotes cardiac fibrosis and heart failure in diabetic hearts through stimulation of EndoMT as these effects did not occur in hearts from transgenic mice with endothelial cell specific endothelin-1 deletion [170].

Connective Tissue Growth Factor (CTGF), also known as $\mathrm{CCN} 2$, is another pleotropic growth factor that has emerged as an important mediator of normal and pathological tissue fibrotic responses [171-174] and has been suggested to play a crucial role in SSc tissue fibrosis. TGF- $\beta$ causes potent stimulation of CTGF synthesis in fibroblasts, vascular smooth muscle cells, and endothelial cells, and numerous studies have shown that CTGF represents a downstream mediator of TGF- $\beta$ fibrogenic effects [175-177]. Despite the important role of CTGF in the pathogenesis of tissue fibrosis and its potential participation in SSc owing to the well-recognized functional interactions with TGF- $\beta$, its possible participation in the EndoMT process has not been investigated, although a very recent study showed that elevated levels of CTGF in SSc microvascular endothelial cells were capable of stimulating fibroblast activation and increased motility and invasion in in vitro studies. Further investigation indicated that these effects were mediated by CTGF-induced increased expression of TGF- $\beta$ in the target fibroblasts [178]. Another very recent study demonstrated that CTGF is one of the target genes of 
Snail-1 and showed a remarkable increase in CTGF expression in endothelial cells following experimentally-induced overexpression of Snail-1 [179].

6.5. Role of MicroRNAs in the Regulation of EndoMT. MicroRNAs (miRNAs) are small ( $\sim 22$ nucleotides), evolutionarily conserved noncoding RNAs which play important roles in the regulation of the expression of a large number of protein coding genes at the posttranscriptional level [180183]. The mechanisms involved in posttranscriptional regulation of gene expression by miRNAs are complex and require the sequence-specific complementary binding to the $3^{\prime}$ untranslated region (UTR) of target mRNAs suppressing their expression by either inhibiting mRNA translation or facilitating their degradation [184-186]. Recent interest has been devoted to elucidating their participation in tissue fibrosis and fibrotic diseases [187-190]. Indeed, several miRNAs have been shown to be involved in SSc tissue fibrosis [191-197], displaying either profibrotic or antifibrotic effects. Furthermore, it has been shown that numerous miRNAs display strong modulation of their expression by TGF- $\beta$ [198], although the implications of these TGF- $\beta$-miRNA interactions have not been fully elucidated. Moreover, several studies have described potential modulatory effects of miRNA on EMT [199], although their participation in EndoMT has not been examined in detail. However, recent reports described results indicating that miRNA21 partially mediated the TGF$\beta$-induced EndoMT in human umbilical vein endothelial cells [200] and that several miRNAs were either increased or decreased during TGF- $\beta 2$-induced EndoMT in murine cardiac endothelial cells [120].

\section{Conclusions and Future Directions}

Scleroderma or Systemic Sclerosis (SSc) is a systemic autoimmune disease of unknown etiology characterized by progressive fibrosis of skin and multiple internal organs and severe alterations in the microvasculature [1]. SSc is the third most common systemic inflammatory autoimmune disease and has the highest case-specific mortality among this group of idiopathic disorders. Whereas remarkable therapeutic advances have recently been accomplished for Rheumatoid Arthritis and Systemic Lupus Erythematosus, there is currently no effective disease-modifying therapy for SSc. Therefore, there is an urgent unmet need for the development of effective disease-modifying therapies to improve the devastating health consequences and high mortality caused by the disease. The effector cells ultimately responsible for the severe fibroproliferative process in SSc are activated myofibroblasts. These cells display very active protein synthesis producing increased amounts of ECM proteins and acquiring a motile and contractile phenotype expressing a high level of $\alpha$-SMA [12-14]. Although it is widely recognized that there are numerous inflammatory and immunological events in the pathogenesis of SSc, myofibroblasts have been recognized as the crucial determinant of the fibrotic process in SSc and other fibrotic disorders $[6,11-13$, 201-203]. Furthermore, their accumulation in affected tissues and the persistence of their elevated biosynthetic functions are the primary determinants of the extent and severity of the clinical manifestations in SSc, and of its clinical course, response to therapy, prognosis, and overall mortality. Thus, activated myofibroblasts have become an important target for SSc disease-modifying therapeutic approaches [204-206].

Extensive research studies have shown that these cells originate from several sources [94, 207], including expansion and phenotypic activation of resident tissue fibroblasts and migration and tissue accumulation of bone marrow-derived circulating fibrocytes, or from epithelial cells which have undergone EMT. More recent studies, however, have demonstrated that endothelial cells are also capable of undergoing a phenotypic change to activated mesenchymal cells in a complex process known as EndoMT. Although there are very few studies that have examined the possible participation of EndoMT in the initiation and progression of the fibrotic and fibroproliferative processes in SSc, it is expected that given its potential importance in the pathogenesis of this currently incurable disease this area of investigation may attract further scientific attention.

Despite the relatively recent research interest in the role of EndoMT in the SSc pathogenesis, important components of the complex pathway of TGF- $\beta$-induced EndoMT and the molecular mechanisms involved in the generation of activated tissue myofibroblasts have already been identified. These observations suggest that targeting components of these pathways may be a feasible therapeutic goal to modify crucial steps in the development of SSc fibroproliferative vasculopathy [208]. Furthermore, the important role that miRNAs have been shown to play in the regulation of gene expression has clearly opened the possibility of developing a novel therapeutic approach for SSc by targeting these extremely versatile noncoding RNA species. Obviously, subsequent preclinical studies employing suitable animal models will be required to further support the potential therapeutic role of EndoMT and/or miRNA modulation for the fibrosis and proliferative vasculopathy of SSc.

\section{Acknowledgments}

This work is supported by the National Institute of Arthritis and Musculoskeletal and Skin Diseases, part of the National Institutes of Health, under Award no. AM19606. The content is solely the responsibility of the author and does not necessarily represent the official views of the National Institutes of Health. The expert assistance of Kenneth Brown is duly acknowledged. The author thanks Drs. Joel Rosenbloom and Sonsoles Piera-Velazquez for the valuable comments and for critical reading of this paper.

\section{References}

[1] A. Gabrielli, E. V. Avvedimento, and T. Krieg, "Scleroderma," The New England Journal of Medicine, vol. 360, no. 19, pp. 19892003, 2009.

[2] S. A. Jimenez and C. T. Derk, "Following the molecular pathways toward an understanding of the pathogenesis of systemic 
sclerosis," Annals of Internal Medicine, vol. 140, no. 1, pp. 37-50, 2004.

[3] J. Varga and D. Abraham, "Systemic sclerosis: a prototypic multisystem fibrotic disorder," Journal of Clinical Investigation, vol. 117, no. 3, pp. 557-567, 2007.

[4] T. R. Katsumoto, M. L. Whitfield, and M. K. Connolly, "The pathogenesis of systemic sclerosis," Annual Review of Pathology: Mechanisms of Disease, vol. 6, pp. 509-537, 2011.

[5] C. P. Denton, C. M. Black, and D. J. Abraham, "Mechanisms and consequences of fibrosis in systemic sclerosis," Nature Clinical Practice Rheumatology, vol. 2, pp. 134-144, 2006.

[6] T. A. Wynn, "Common and unique mechanisms regulate fibrosis in various fibroproliferative diseases," Journal of Clinical Investigation, vol. 117, no. 3, pp. 524-529, 2007.

[7] J. A. Varga and M. Trojanowska, "Fibrosis in systemic sclerosis," Rheumatic Disease Clinics of North America, vol. 34, no. 1, pp. 115-143, 2008.

[8] M. Matucci-Cerinic, B. Kahaleh, and F. M. Wigley, "Systemic sclerosis, (scleroderma, SSc) is a vascular disease," Arthritis and Rheumatism, vol. 65, no. 8, pp. 1953-1962, 2013.

[9] B. Kahaleh, "Vascular disease in scleroderma: mechanisms of vascular injury," Rheumatic Disease Clinics of North America, vol. 34, no. 1, pp. 57-71, 2008.

[10] M. Trojanowska, "Cellular and molecular aspects of vascular dysfunction in systemic sclerosis," Nature Reviews Rheumatology, vol. 6, no. 8, pp. 453-460, 2010.

[11] T. A. Wynn and T. R. Ramalingam, "Mechanisms of fibrosis: therapeutic translation for fibrotic disease," Nature Medicine, vol. 18, pp. 1028-1040, 2012.

[12] T. Krieg, D. Abraham, and R. Lafyatis, "Fibrosis in connective tissue disease: the role of the myofibroblast and fibroblastepithelial cell interactions," Arthritis Research and Therapy, vol. 9, supplement 2, article S4, 2007.

[13] D. J. Abraham, B. Eckes, V. Rajkumar, and T. Krieg, "New developments in fibroblast and myofibroblast biology: implications for fibrosis and scleroderma," Current Rheumatology Reports, vol. 9, no. 2, pp. 136-143, 2007.

[14] T. Z. Kirk, M. E. Mark, C. C. Chua, B. H. Chua, and M. D. Mayes, "Myofibroblasts from scleroderma skin synthesize elevated levels of collagen and tissue inhibitor of metalloproteinase (TIMP-1) with two forms of TIMP-1," The Journal of Biological Chemistry, vol. 270, no. 7, pp. 3423-3428, 1995.

[15] E. Romano, M. Manetti, S. Guiducci, C. Ceccarelli, Y. Allanore, and M. Matucci-Cerinic, "The genetics of systemic sclerosis: an update," Clinical and Experimental Rheumatology, vol. 29, no. 2, pp. S75-S86, 2011.

[16] M. D. Mayes, "The genetics of scleroderma: looking into the postgenomic era," Current Opinion in Rheumatology, vol. 24, no. 6, pp. 677-684, 2012.

[17] J. C. A. Broen, M. J. H. Coenen, and T. R. D. J. Radstake, "Genetics of systemic sclerosis: an update," Current Rheumatology Reports, vol. 14, no. 1, pp. 11-21, 2012.

[18] J. E. Martín, L. Bossini-Castillo, and J. Martín, "Unraveling the genetic component of systemic sclerosis," Human Genetics, vol. 131, no. 7, pp. 1023-1037, 2012.

[19] C. Chizzolini, N. C. Brembilla, E. Montanari, and M. Truchetet, "Fibrosis and immune dysregulation in systemic sclerosis," Autoimmunity Reviews, vol. 10, no. 5, pp. 276-281, 2011.

[20] Y. S. Gu, J. Kong, G. S. Cheema, C. L. Keen, G. Wick, and M. E. Gershwin, "The immunobiology of systemic sclerosis," Seminars in Arthritis and Rheumatism, vol. 38, no. 2, pp. 132160, 2008.
[21] M. R. York, "Novel insights on the role of the innate immune system in systemic sclerosis," Expert Review of Clinical Immunology, vol. 7, no. 4, pp. 481-489, 2011.

[22] T. A. Wynn, "Cellular and molecular mechanisms of fibrosis," Journal of Pathology, vol. 214, no. 2, pp. 199-210, 2008.

[23] V. Steen, C. P. Denton, J. E. Pope, and M. Matucci-Cerinic, "Digital ulcers: overt vascular disease in systemic sclerosis," Rheumatology, vol. 48, supplement 3, pp. iiil9-iii24, 2009.

[24] A. L. Herrick, "The pathogenesis, diagnosis and treatment of Raynaud phenomenon," Nature Reviews Rheumatology, vol. 8, pp. 469-479, 2012.

[25] V. D. Steen, "Scleroderma renal crisis," Rheumatic Disease Clinics of North America, vol. 29, no. 2, pp. 315-333, 2003.

[26] L. Mouthon, A. Bérezné, G. Bussone, L. Noël, P. M. Villiger, and L. Guillevin, "Scleroderma renal crisis: a rare but severe complication of systemic sclerosis," Clinical Reviews in Allergy and Immunology, vol. 40, no. 2, pp. 84-91, 2011.

[27] C. P. Denton and C. M. Black, "Pulmonary hypertension in systemic sclerosis," Rheumatic Disease Clinics of North America, vol. 29, no. 2, pp. 335-349, 2003.

[28] A. Ramirez and J. Varga, "Pulmonary arterial hypertension in systematic sclerosis: clinical manifestations, pathophysiology, evaluation, and management," Treatments in Respiratory Medicine, vol. 3, no. 6, pp. 339-352, 2004.

[29] S. Chatterjee, "Pulmonary hypertension in systemic sclerosis," Seminars in Arthritis and Rheumatism, vol. 41, no. 1, pp. 19-37, 2011.

[30] M. Cutolo, A. Sulli, and V. Smith, "Assessing microvascular changes in systemic sclerosis diagnosis and management," Nature Reviews Rheumatology, vol. 6, no. 10, pp. 578-587, 2010.

[31] W. Grassi, P. D. Medico, F. Izzo, and C. Cervini, "Microvascular involvement in systemic sclerosis: capillaroscopic findings," Seminars in Arthritis and Rheumatism, vol. 30, no. 6, pp. 397402, 2001.

[32] A. A. Shah, F. M. Wigley, and L. K. Hummers, "Telangiectases in scleroderma: a potential clinical marker of pulmonary arterial hypertension," Journal of Rheumatology, vol. 37, no. 1, pp. 98$104,2010$.

[33] M. M. El-Omar, A. P. Jenkins, K. Hollowood, A. K. Banerjee, and R. P. H. Thompson, "Gastric telangiectasis: a rare cause of severe blood loss in CREST syndrome," Postgraduate Medical Journal, vol. 70, no. 822, pp. 302-304, 1994.

[34] B. Jharap, L. G. Koudstaal, E. A. Neefjes-Borst, and S. J. B. van Weyenberg, "Colonic telangiectasias in progressive systemic sclerosis," Endoscopy, vol. 44, supplement 2, pp. E42-E43, 2012.

[35] E. V. Lally and S. A. Jimenez, "Impotence in progressive systemic sclerosis," Annals of Internal Medicine, vol. 95, no. 2, pp. 150-153, 1981.

[36] S. Sukenik, J. Horowitz, D. Buskila, J. M. Abarbanel, L. Lismer, and I. Avinoach, "Impotence in systemic sclerosis," Annals of Internal Medicine, vol. 106, no. 6, pp. 910-911, 1987.

[37] C. Foocharoen, A. Tyndall, E. Hachulla et al., "Erectile dysfunction is frequent in systemic sclerosis and associated with severe disease: a study of the EULAR scleroderma trial and research group," Arthritis Research and Therapy, vol. 14, no. 1, article R37, 2012.

[38] C. T. Derk and S. A. Jimenez, "Acute myocardial infarction in systemic sclerosis patients: a case series," Clinical Rheumatology, vol. 26, no. 6, pp. 965-968, 2007.

[39] Y. Allanore and C. Meune, "Primary myocardial involvement in systemic sclerosis: evidence for a microvascular origin," Clinical 
and Experimental Rheumatology, vol. 28, no. 5, pp. S48-S53, 2010.

[40] M. Watson, R. J. Hally, P. A. McCue, J. Varga, and S. A. Jiménez, "Gastric antral vascular ectasia (watermelon stomach) in patients with systemic sclerosis," Arthritis and Rheumatism, vol. 39, no. 2, pp. 341-346, 1996.

[41] K. M. Ingraham, M. S. O’Brien, M. A. X. Shenin, C. T. Derk, and V. D. Steen, "Gastric antral vascular ectasia in systemic sclerosis: demographics and disease predictors," Journal of Rheumatology, vol. 37, no. 3, pp. 603-607, 2010.

[42] E. W. Hung, M. D. Mayes, R. Sharif, S. Assassi, V. I. Machicao, and C. Hosing, "Gastric antral vascular ectasia and its clinical correlates in patients with early diffuse systemic sclerosis in the SCOT trial," Journal of Rheumatology, vol. 40, no. 4, pp. 455460, 2013.

[43] J. Busquets, Y. Lee, L. Santamarina et al., "Acute retinal artery occlusion in systemic sclerosis: a rare manifestation of systemic sclerosis fibroproliferative vasculopathy," Seminars in Arthritis and Rheumatism, 2013.

[44] M. Minasian, M. Stanford, E. Graham, C. P. Denton, and C. Black, "Bilateral ischaemic retinal vasculopathy in scleroderma," The British Journal of Ophthalmology, vol. 89, no. 8, pp. 1064-1065, 2005.

[45] M. H. Taylor, J. A. McFadden, M. B. Bolster, and R. M. Silver, "Ulnar artery involvement in systemic sclerosis (scleroderma)," Journal of Rheumatology, vol. 29, no. 1, pp. 102-106, 2002.

[46] P. Youssef, H. Englert, and J. Bertouch, "Large vessel occlusive disease associated with CREST syndrome and scleroderma," Annals of the Rheumatic Diseases, vol. 52, no. 6, pp. 464-466, 1993.

[47] U. Müller-Ladner, O. Distler, L. Ibba-Manneschi, E. Neumann, and S. Gay, "Mechanisms of vascular damage in systemic sclerosis," Autoimmunity, vol. 42, no. 7, pp. 587-595, 2009.

[48] D. Abraham and O. Distler, "How does endothelial cell injury start? The role of endothelin in systemic sclerosis," Arthritis Research and Therapy, vol. 9, supplement 2, article S2, 2007.

[49] J. P. Pandey and E. C. LeRoy, "Human cytomegalovirus and the vasculopathies of autoimmune diseases (especially scleroderma), allograft rejection, and coronary restenosis," Arthritis and Rheumatism, vol. 41, no. 1, pp. 10-15, 1998.

[50] M. Neidhart, S. Kuchen, O. Distler et al., "Increased serum levels of antibodies against human cytomegalovirus and prevalence of autoantibodies in systemic sclerosis," Arthritis and Rheumatism, vol. 42, pp. 389-392, 1999.

[51] Y. Renaudineau, R. Revelen, Y. Levy et al., "Anti-endothelial cell antibodies in systemic sclerosis," Clinical and Diagnostic Laboratory Immunology, vol. 6, no. 2, pp. 156-160, 1999.

[52] F. Drenk and H. R. G. Deicher, "Pathophysiological effects of endothelial cytotoxic activity derived from sera of patients with progressive systemic sclerosis," Journal of Rheumatology, vol. 15, no. 3, pp. 468-474, 1988.

[53] N. Del Papa, G. Colombo, N. Fracchiolla et al., "Circulating endothelial cells as a marker of ongoing vascular disease in systemic sclerosis," Arthritis and Rheumatism, vol. 50, no. 4, pp. 1296-1304, 2004.

[54] J. Avouac, F. Juin, J. Wipff et al., "Circulating endothelial progenitor cells in systemic sclerosis: association with disease severity," Annals of the Rheumatic Diseases, vol. 67, no. 10, pp. 1455-1460, 2008.

[55] Y. Allanore, F. Batteux, J. Avouac, N. Assous, B. Weill, and A. Kahan, "Levels of circulating endothelial progenitor cells in systemic sclerosis," Clinical and Experimental Rheumatology, vol. 25, no. 1, pp. 60-66, 2007.

[56] A. Kuryliszyn-Moskal, P. A. Klimiuk, and S. Sierakowski, "Soluble adhesion molecules (sVCAM-1, sE-selectin), vascular endothelial growth factor (VEGF) and endothelin-1 in patients with systemic sclerosis: relationship to organ systemic involvement," Clinical Rheumatology, vol. 24, no. 2, pp. 111-116, 2005.

[57] G. N. Andersen, K. Caidahl, E. Kazzam et al., "Correlation between increased nitric oxide production and markers of endothelial activation in systemic sclerosis: findings with the soluble adhesion molecules E-selectin, intercellular adhesion molecule 1, and vascular cell adhesion molecule 1," Arthritis and Rheumatism, vol. 43, no. 5, pp. 1085-1093, 2000.

[58] M. J. Mulligan-Kehoe and M. Simons, "Vascular disease in scleroderma: angiogenesis and vascular repair," Rheumatic Disease Clinics of North America, vol. 34, no. 1, pp. 73-79, 2008.

[59] M. M. Cerinic, G. Valentini, G. G. Sorano et al., "Blood coagulation, fibrinolysis, and markers of endothelial dysfunction in systemic sclerosis," Seminars in Arthritis and Rheumatism, vol. 32, no. 5, pp. 285-295, 2003.

[60] K. R. Stenmark, K. A. Fagan, and M. G. Frid, "Hypoxia-induced pulmonary vascular remodeling: cellular and molecular mechanisms," Circulation Research, vol. 99, no. 7, pp. 675-691, 2006.

[61] C. Beyer, G. Schett, S. Gay, O. Distler, and J. H. W. Distler, "Hypoxia. Hypoxia in the pathogenesis of systemic sclerosis," Arthritis Research \& Therapy, vol. 11, no. 2, p. 220, 2009.

[62] M. E. Anderson, T. L. Moore, S. Hollis, S. Clark, M. I. V. Jayson, and A. L. Herrick, "Endothelial-dependent vasodilatation is impaired in patients with systemic sclerosis, as assessed by low dose iontophoresis," Clinical and Experimental Rheumatology, vol. 21, no. 3, article 403, 2003.

[63] R. Livi, L. Teghini, S. Generini, and M. Matucci-Cerinic, "The loss of endothelium-dependent vascular tone control in systemic sclerosis," Chest, vol. 119, no. 2, pp. 672-673, 2001.

[64] B. Kahaleh and M. Matucci-Cerinic, "Raynaud's phenomenon and scleroderma: dysregulated neuroendothelial control of vascular tone," Arthritis and Rheumatism, vol. 38, no. 1, pp. 14, 1995.

[65] J. Cailes, S. Winter, R. M. du Bois, and T. W. Evans, "Defective endothelially mediated pulmonary vasodilation in systemic sclerosis," Chest, vol. 114, no. 1, pp. 178-184, 1998.

[66] A. Leask, "The role of endothelin-1 signaling in the fibrosis observed in systemic sclerosis," Pharmacological Research, vol. 63, no. 6, pp. 502-503, 2011.

[67] N. Giordano, P. Papakostas, G. Pecetti, and R. Nuti, "Cytokine modulation by endothelin-1 and possible therapeutic implications in systemic sclerosis," Journal of Biological Regulators and Homeostatic Agents, vol. 25, no. 4, pp. 487-492, 2011.

[68] K. Yamane, H. Kashiwagi, N. Suzuki et al., "Elevated plasma levels of endothelin-1 in systemic sclerosis," Arthritis and Rheumatism, vol. 34, no. 2, pp. 243-244, 1991.

[69] K. Yamane, T. Miyauchi, N. Suzuki et al., "Significance of plasma endothelin-1 levels in patients with systemic sclerosis," Journal of Rheumatology, vol. 19, no. 10, pp. 1566-1571, 1992.

[70] A. D. Cambrey, N. K. Harrison, K. E. Dawes et al., "Increased levels of endothelin-1 in bronchoalveolar lavage fluid from patients with systemic sclerosis contribute to fibroblast mitogenic activity in vitro," The American Journal of Respiratory Cell and Molecular Biology, vol. 11, no. 4, pp. 439-445, 1994.

[71] R. Vancheeswaran, T. Magoulas, G. Efrat et al., "Circulating endothelin-1 levels in systemic sclerosis subsets-a marker of 
fibrosis or vasular dysfunction?" Journal of Rheumatology, vol. 21, no. 10, pp. 1838-1844, 1994.

[72] S. Morelli, C. Ferri, E. Polettini et al., "Plasma endothelin-1 levels, pulmonary hypertension, and lung fibrosis in patients with systemic sclerosis," The American Journal of Medicine, vol. 99, no. 3, pp. 255-260, 1995.

[73] S. Xu, C. P. Denton, A. Holmes, M. R. Dashwood, D. J. Abraham, and C. M. Black, "Endothelins: effect on matrix biosynthesis and proliferation in normal and scleroderma fibroblasts," Journal of Cardiovascular Pharmacology, vol. 31, no. 1, pp. S360-S363, 1998.

[74] X. Shi-Wen, C. P. Denton, M. R. Dashwood et al., "Fibroblast matrix gene expression and connective tissue remodeling: role of endothelin-1," Journal of Investigative Dermatology, vol. 116, no. 3, pp. 417-425, 2001.

[75] X. Shi-Wen, E. A. Renzoni, L. Kennedy et al., "Endogenous endothelin-1 signaling contributes to type I collagen and CCN2 overexpression in fibrotic fibroblasts," Matrix Biology, vol. 26, no. 8, pp. 625-632, 2007.

[76] X. Shi-wen, L. Kennedy, E. A. Renzoni et al., "Endothelin is a downstream mediator of profibrotic responses to transforming growth factor $\beta$ in human lung fibroblasts," Arthritis and Rheumatism, vol. 56, no. 12, pp. 4189-4194, 2007.

[77] I. Chrobak, S. Lenna, L. Stawski, and M. Trojanowska, "Interferon- $\gamma$ promotes vascular remodeling in human microvascular endothelial cells by upregulating endothelin (ET)-1 and transforming growth factor (TGF) $\beta 2$," Journal of Cellular Physiology, vol. 228, no. 8, pp. 1774-1783, 2013.

[78] A. E. Koch and O. Distler, "Vasculopathy and disordered angiogenesis in selected rheumatic diseases: rheumatoid arthritis and systemic sclerosis," Arthritis Research and Therapy, vol. 9, supplement 2, article S3, 2007.

[79] J. H. W. Distler, S. Gay, and O. Distler, "Angiogenesis and vasculogenesis in systemic sclerosis," Rheumatology, vol. 45, no. 3, pp. iii26-iii27, 2006.

[80] J. Wipff, J. Avouac, D. Borderie et al., "Disturbed angiogenesis in systemic sclerosis: high levels of soluble endoglin," Rheumatology, vol. 47, no. 7, pp. 972-975, 2008.

[81] N. Del Papa, N. Quirici, D. Soligo et al., "Bone marrow endothelial progenitors are defective in systemic sclerosis," Arthritis and Rheumatism, vol. 54, no. 8, pp. 2605-2615, 2006.

[82] M. Kuwana, Y. Okazaki, H. Yasuoka, Y. Kawakami, and Y. Ikeda, "Defective vasculogenesis in systemic sclerosis," The Lancet, vol. 364, no. 9434, pp. 603-610, 2004.

[83] O. Distler, J. H. W. Distler, A. Scheid et al., "Uncontrolled expression of vascular endothelial growth factor and its receptors leads to insufficient skin angiogenesis in patients with systemic sclerosis," Circulation Research, vol. 95, no. 1, pp. 109116, 2004.

[84] T. Nevskaya, S. Bykovskaia, E. Lyssuk et al., "Circulating endothelial progenitor cells in systemic sclerosis: relation to impaired angiogenesis and cardiovascular manifestations," Clinical and Experimental Rheumatology, vol. 26, no. 3, pp. 421-429, 2008.

[85] P. Cipriani, S. Guiducci, I. Miniati et al., "Impairment of endothelial cell differentiation from bone marrow-derived mesenchymal stem cells: new insight into the pathogenesis of systemic sclerosis," Arthritis and Rheumatism, vol. 56, no. 6, pp. 1994-2004, 2007.

[86] J. N. Fleming and S. M. Schwartz, "The pathology of scleroderma vascular disease," Rheumatic Disease Clinics of North America, vol. 34, no. 1, pp. 41-55, 2008.
[87] F. J. de Lange, A. F. M. Moorman, R. H. Anderson et al., "Lineage and morphogenetic analysis of the cardiac valves," Circulation Research, vol. 95, no. 6, pp. 645-654, 2004.

[88] E. Arciniegas, C. Y. Neves, L. M. Carrillo, E. A. Zambrano, and R. Ramírez, "Endothelial-mesenchymal transition occurs during embryonic pulmonary artery development," Endothelium, vol. 12, no. 4, pp. 193-200, 2005.

[89] A. de Vlaming, K. Sauls, Z. Hajdu et al., "Atrioventricular valve development: new perspectives on an old theme," Differentiation, vol. 84, no. 1, pp. 103-116, 2012.

[90] S. Piera-Velazquez, Z. Li, and S. A. Jimenez, "Role of endothelial-mesenchymal transition (EndoMT) in the pathogenesis of fibrotic disorders," The American Journal of Pathology, vol. 179, no. 3, pp. 1074-1080, 2011.

[91] J. He, Y. Xu, and K. Kanasaki, "Role of endothelial-tomesenchymal transition in renal fibrosis of chronic kidney disease," Clinical and Experimental Nephrology, vol. 17, no. 4, pp. 488-497, 2013.

[92] J. Li and J. F. Bertram, "Endothelial-myofibroblast transition, a new player in diabetic renal fibrosis," Nephrology, vol. 15, no. 5, pp. 507-512, 2010.

[93] F. Rieder, S. P. Kessler, G. A. West et al., "Inflammation-induced endothelial-to-mesenchymal transition: a novel mechanism of intestinal fibrosis," The American Journal of Pathology, vol. 179, no. 5, pp. 2660-2673, 2011.

[94] V. S. Lebleu, G. Taduri, J. O’Connell et al., "Origin and function of myofibroblasts in kidney fibrosis," Nature Medicine, vol. 19, no. 8, pp. 1047-1053, 2013.

[95] E. M. Zeisberg, S. E. Potenta, H. Sugimoto, M. Zeisberg, and R. Kalluri, "Fibroblasts in kidney fibrosis emerge via endothelialto-mesenchymal transition," Journal of the American Society of Nephrology, vol. 19, no. 12, pp. 2282-2287, 2008.

[96] E. M. Zeisberg, O. Tarnavski, M. Zeisberg et al., "Endothelialto-mesenchymal transition contributes to cardiac fibrosis," Nature Medicine, vol. 13, no. 8, pp. 952-961, 2007.

[97] A. Kizu, D. Medici, and R. Kalluri, "Endothelial-mesenchymal transition as a novel mechanism for generating myofibroblasts during diabetic nephropathy," The American Journal of Pathology, vol. 175, no. 4, pp. 1371-1373, 2009.

[98] S. Speca, I. Giusti, F. Rieder, and G. Latella, "Cellular and molecular mechanisms of intestinal fibrosis," World Journal of Gastroenterology, vol. 18, no. 28, pp. 3635-3661, 2012.

[99] Y. Sato and Y. Nakanuma, "Role of endothelial-mesenchymal transition in idiopathic portal hypertension," Histology and Histopathology, vol. 28, pp. 145-154, 2013.

[100] E. Arciniegas, M. G. Frid, I. S. Douglas, and K. R. Stenmark, "Perspectives on endothelial-to-mesenchymal transition: potential contribution to vascular remodeling in chronic pulmonary hypertension," The American Journal of PhysiologyLung Cellular and Molecular Physiology, vol. 293, no. 1, pp. L1L8, 2007.

[101] S. Piera-Velazquez and S. A. Jimenez, "Molecular mechanisms of endothelial to mesenchymal cell transition (EndoMT) in experimentally induced fibrotic diseases," Fibrogenesis and Tissue Repair, vol. 5, supplement 1, article S7, 2012.

[102] M. Goumans, Z. Liu, and P. T. Dijke, "TGF- $\beta$ signaling in vascular biology and dysfunction," Cell Research, vol. 19, no. 1, pp. 116-127, 2009.

[103] D. Medici, S. Potenta, and R. Kalluri, “Transforming growth factor- $\beta 2$ promotes Snail-mediated endothelial-mesenchymal 
transition through convergence of Smad-dependent and Smadindependent signalling," Biochemical Journal, vol. 437, no. 3, pp. 515-520, 2011.

[104] L. A. van Meeteren and P. T. Dijke, "Regulation of endothelial cell plasticity by TGF- $\beta$," Cell and Tissue Research, vol. 347, no. 1, pp. 177-186, 2012.

[105] M. B. Sporn, A. B. Roberts, L. M. Wakefield, and R. K. Assoian, "Transforming growth factor factor- $\beta$ : biological function and chemical structure," Science, vol. 233, no. 4763, pp. 532-534, 1986.

[106] A. B. Roberts, K. C. Flanders, U. I. Heine et al., “Transforming growth factor-beta: multifunctional regulator of differentiation and development," Philosophical transactions of the Royal Society of London B, vol. 327, no. 1239, pp. 145-154, 1990.

[107] G. C. Blobe, W. P. Schiemann, and H. F. Lodish, "Role of transforming growth factor $\beta$ in human disease," The New England Journal of Medicine, vol. 342, no. 18, pp. 1350-1358, 2000.

[108] W. A. Border and N. A. Noble, "Transforming growth factor $\beta$ in tissue fibrosis," The New England Journal of Medicine, vol. 331, no. 19, pp. 1286-1292, 1994.

[109] R. A. Ignotz and J. Massagué, “Transforming growth factor$\beta$ stimulates the expression of fibronectin and collagen and their incorporation into the extracellular matrix," The Journal of Biological Chemistry, vol. 261, no. 9, pp. 4337-4345, 1986.

[110] J. Varga and S. A. Jimenez, "Stimulation of normal human fibroblast collagen production and processing by transforming growth factor," Biochemical and Biophysical Research Communications, vol. 138, no. 2, pp. 974-980, 1986.

[111] J. Varga, J. Rosenbloom, and S. A. Jimenez, “Transforming growth factor $\beta$ (TGF $\beta$ ) causes a persistent increase in steadystate amounts of type I and type III collagen and fibronectin mRNAs in normal human dermal fibroblasts," Biochemical Journal, vol. 247, no. 3, pp. 597-604, 1987.

[112] A. B. Roberts, U. I. Heine, K. C. Flanders, and M. B. Sporn, "Transforming growth factor- $\beta$. Major role in regulation of extracellular matrix," Annals of the New York Academy of Sciences, vol. 580, pp. 225-232, 1990.

[113] R. J. McAnulty, J. S. Campa, A. D. Cambrey, and G. J. Laurent, "The effect of transforming growth factor $\beta$ on rates of procollagen synthesis and degradation in vitro," Biochimica et Biophysica Acta, vol. 1091, no. 2, pp. 231-235, 1991.

[114] D. R. Edwards, G. Murphy, J. J. Reynolds et al., “Transforming growth factor beta modulates the expression of collagenase and metalloproteinase inhibitor," EMBO Journal, vol. 6, no. 7, pp. 1899-1904, 1987.

[115] H. Ihn, "Autocrine TGF- $\beta$ signaling in the pathogenesis of systemic sclerosis," Journal of Dermatological Science, vol. 49, no. 2, pp. 103-113, 2008.

[116] Z. Li and S. A. Jimenez, "Protein kinase C $\delta$ and c-Abl kinase are required for transforming growth factor $\beta$ induction of endothelial-mesenchymal transition in vitro," Arthritis and Rheumatism, vol. 63, no. 8, pp. 2473-2483, 2011.

[117] Y. Yoshimatsu and T. Watabe, "Roles of TGF- $\beta$ signals in endothelial-mesenchymal transition during cardiac fibrosis," International Journal of Inflammation, vol. 2011, Article ID 724080, 8 pages, 2011.

[118] F. Lin, N. Wang, and T. C. Zhang, "The role of endothelialmesenchymal transition in development and pathological process," IUBMB Life, vol. 64, no. 9, pp. 717-723, 2012.
[119] J. Garcia, M. J. Sandi, P. Cordelier et al., "Tiel deficiency induces endothelial-mesenchymal transition," EMBO Reports, vol. 13, no. 5, pp. 431-439, 2012.

[120] A. K. Ghosh, V. Nagpal, J. W. Covington, M. A. Michaels, and D. E. Vaughan, "Molecular basis of cardiac endothelialto-mesenchymal transition (EndMT): differential expression of microRNAs during EndMT," Cellular Signalling, vol. 24, no. 5, pp. 1031-1036, 2012.

[121] H. Mihira, H. I. Suzuki, Y. Akatsu et al., "TGF- $\beta$-induced mesenchymal transition of MS-1 endothelial cells requires Smad-dependent cooperative activation of Rho signals and MRTF-A," Journal of Biochemistry, vol. 151, no. 2, pp. 145-156, 2012.

[122] M. Reis and S. Liebner, "Wnt signaling in the vasculature," Experimental Cell Research, vol. 319, no. 9, pp. 1317-1323, 2013.

[123] C. Niehrs, "The complex world of WNT receptor signalling," Nature Reviews Molecular Cell Biology, vol. 13, pp. 767-779, 2012.

[124] H. Clevers and R. Nusse, "Wnt/ $\beta$-catenin signaling and disease," Cell, vol. 149, no. 6, pp. 1192-1205, 2012.

[125] P. Herr, G. Hausmann, and K. Basler, "WNT secretion and signalling in human disease," Trends in Molecular Medicine, vol. 18, no. 8, pp. 483-493, 2012.

[126] R. Lafyatis, "Connective tissue disease: SSc-fibrosis takes flight with Wingless inhibition," Nature Reviews Rheumatology, vol. 8, pp. 441-442, 2012.

[127] C. Beyer, A. Schramm, A. Akhmetshina et al., " $\beta$-catenin is a central mediator of pro-fibrotic Wnt signaling in systemic sclerosis," Annals of the Rheumatic Diseases, vol. 71, no. 5, pp. 761-767, 2012.

[128] J. Wei, F. Fang, A. P. Lam et al., "Wnt/ $\beta$-catenin signaling is hyperactivated in systemic sclerosis and induces Smaddependent fibrotic responses in mesenchymal cells," Arthritis and Rheumatism, vol. 64, no. 8, pp. 2734-2745, 2012.

[129] A. P. Lam, A. S. Flozak, S. Russell et al., "Nuclear $\beta$-catenin is increased in systemic sclerosis pulmonary fibrosis and promotes lung fibroblast migration and proliferation," The American Journal of Respiratory Cell and Molecular Biology, vol. 45, no. 5, pp. 915-922, 2011.

[130] L. Attisano and E. Labbé, “TGF $\beta$ and Wnt pathway cross-talk," Cancer and Metastasis Reviews, vol. 23, no. 1-2, pp. 53-61, 2004.

[131] P. Minoo and C. Li, "Cross-talk between transforming growth factor- $\beta$ and Wingless/Int pathways in lung development and disease," International Journal of Biochemistry and Cell Biology, vol. 42, no. 6, pp. 809-812, 2010.

[132] P. Zhang, Y. Cai, A. Soofi, and G. R. Dressler, "Activation of Wnt1l by transforming growth factor- $\beta$ drives mesenchymal gene expression through non-canonical Wnt protein signaling in renal epithelial cells," The Journal of Biological Chemistry, vol. 287, no. 25, pp. 21290-21302, 2012.

[133] A. Akhmetshina, K. Palumbo, C. Dees et al., "Activation of canonical Wnt signalling is required for TGF- $\beta$-mediated fibrosis," Nature Communications, vol. 3, article 734, 2012.

[134] R. Kalluri and E. G. Neilson, "Epithelial-mesenchymal transition and its implications for fibrosis," Journal of Clinical Investigation, vol. 112, no. 12, pp. 1776-1784, 2003.

[135] M. A. Nieto, "The ins and outs of the epithelial to mesenchymal transition in health and disease," Annual Review of Cell and Developmental Biology, vol. 27, pp. 347-376, 2011.

[136] J. P. Thiery, H. Acloque, R. Y. J. Huang, and M. A. Nieto, "Epithelial-mesenchymal transitions in development and disease," Cell, vol. 139, no. 5, pp. 871-890, 2009. 
[137] K. Lee and C. M. Nelson, "New insights into the regulation of epithelial-mesenchymal transition and tissue fibrosis," International Review of Cell and Molecular Biology, vol. 294, pp. 171-221, 2012.

[138] S. L. Cheng, J. S. Shao, A. Behrmann, K. Krchma, and D. A. Towler, "Dkk1 and MSX2-wnt7b signaling reciprocally regulate the endothelial-mesenchymal transition in aortic endothelial cells," Arteriosclerosis, Thrombosis, and Vascular Biology, vol. 33, pp. 1679-1689, 2013.

[139] S. J. Bray, "Notch signalling: a simple pathway becomes complex," Nature Reviews Molecular Cell Biology, vol. 7, no. 9, pp. 678-689, 2006.

[140] R. Kopan and M. X. G. Ilagan, "The canonical notch signaling pathway: unfolding the activation mechanism," Cell, vol. 137, no. 2, pp. 216-233, 2009.

[141] A. Louvi and S. Artavanis-Tsakonas, "Notch and disease: a growing field," Seminars in Cell and Developmental Biology, vol. 23, no. 4, pp. 473-480, 2012.

[142] A. L. Penton, L. D. Leonard, and N. B. Spinner, "Notch signaling in human development and disease," Seminars in Cell and Developmental Biology, vol. 23, no. 4, pp. 450-457, 2012.

[143] R. A. Benson, J. A. Lowrey, J. R. Lamb, and S. E. M. Howie, “The Notch and Sonic hedgehog signalling pathways in immunity," Molecular Immunology, vol. 41, no. 6-7, pp. 715-725, 2004.

[144] F. Radtke, A. Wilson, S. J. C. Mancini, and H. R. MacDonald, "Notch regulation of lymphocyte development and function," Nature Immunology, vol. 5, no. 3, pp. 247-253, 2004.

[145] L. E. Laitman and S. Dahan, "Taking inflammatory bowel disease up a Notch," Immunologic Research, vol. 54, no. 1-3, pp. 69-74, 2012.

[146] R. Bonegio and K. Susztak, "Notch signaling in diabetic nephropathy," Experimental Cell Research, vol. 318, no. 9, pp. 986992, 2012.

[147] N. Sethi and Y. Kang, "Notch signalling in cancer progression and bone metastasis," The British Journal of Cancer, vol. 105, no. 12, pp. 1805-1810, 2011.

[148] M. Noseda, G. McLean, K. Niessen et al., "Notch activation results in phenotypic and functional changes consistent with endothelial-to-mesenchymal transformation," Circulation Research, vol. 94, no. 7, pp. 910-917, 2004.

[149] M. Noseda, Y. Fu, K. Niessen et al., "Smooth muscle $\alpha$-actin is a direct target of Notch/CSL," Circulation Research, vol. 98, no. 12, pp. 1468-1470, 2006.

[150] K. Niessen, Y. Fu, L. Chang, P. A. Hoodless, D. McFadden, and A. Karsan, "Slug is a direct Notch target required for initiation of cardiac cushion cellularization," Journal of Cell Biology, vol. 182, no. 2, pp. 315-325, 2008.

[151] Y. X. Fu, A. Chang, L. Chang et al., "Differential regulation of transforming growth factor $\beta$ signaling pathways by Notch in human endothelial cells," The Journal of Biological Chemistry, vol. 284, no. 29, pp. 19452-19462, 2009.

[152] Y. Fu, A. C. Y. Chang, M. Fournier, L. Chang, K. Niessen, and A. Karsan, "RUNX3 maintains the mesenchymal phenotype after termination of the notch signal," The Journal of Biological Chemistry, vol. 286, no. 13, pp. 11803-11813, 2011.

[153] A. C. Y. Chang, Y. Fu, V. C. Garside et al., "Notch initiates the endothelial-to-mesenchymal transition in the atrioventricular canal through autocrine activation of soluble guanylyl cyclase," Developmental Cell, vol. 21, no. 2, pp. 288-300, 2011.

[154] V. C. Garside, A. C. Chang, A. Karsan, and P. A. Hoodless, "Coordinating Notch, BMP, and TGF- $\beta$ signaling during heart valve development," Cellular and Molecular Life Sciences, vol. 70, no. 16, pp. 2899-2917, 2013.

[155] C. Beyer and J. H. Distler, "Morphogen pathways in systemic sclerosis," Current Rheumatology Reports, vol. 15, no. 1, article 299, 2013.

[156] C. Beyer, C. Dees, and J. H. Distler, "Morphogen pathways as molecular targets for the treatment of fibrosis in systemic sclerosis," Archives of Dermatological Research, vol. 305, no. 1, pp. 1-8, 2013.

[157] G. M. Di Guglielmo, C. Le Roy, A. F. Goodfellow, and J. L. Wrana, "Distinct endocytic pathways regulate TGF- $\beta$ receptor signalling and turnover," Nature Cell Biology, vol. 5, no. 5, pp. 410-421, 2003.

[158] S. Hayes, A. Chawla, and S. Corvera, "TGF $\beta$ receptor internalization into EEA1-enriched early endosomes: role in signaling to Smad2," Journal of Cell Biology, vol. 158, no. 7, pp. 1239-1249, 2002.

[159] C. E. Runyan, H. W. Schnaper, and A. Poncelet, "The role of internalization in transforming growth factor $\beta 1$-induced Smad2 association with Smad anchor for receptor activation (SARA) and Smad2-dependent signaling in human mesangial cells," The Journal of Biological Chemistry, vol. 280, no. 9, pp. 8300-8308, 2005.

[160] F. Del Galdo, M. R. Lisanti, and S. A. Jimenez, "Caveolin1 , transforming growth factor- $\beta$ receptor internalization, and the pathogenesis of systemic sclerosis," Current Opinion in Rheumatology, vol. 20, no. 6, pp. 713-719, 2008.

[161] F. Del Galdo, F. Sotgia, C. J. De Almeida et al., "Decreased expression of caveolin 1 in patients with systemic sclerosis: crucial role in the pathogenesis of tissue fibrosis," Arthritis and Rheumatism, vol. 58, no. 9, pp. 2854-2865, 2008.

[162] E. Tourkina, M. Richard, P. Gööz et al., "Antifibrotic properties of caveolin-1 scaffolding domain in vitro and in vivo," The American Journal of Physiology_Lung Cellular and Molecular Physiology, vol. 294, no. 5, pp. L843-L861, 2008.

[163] O. Le Saux, K. Teeters, S. Miyasato et al., "The role of caveolin-1 in pulmonary matrix remodeling and mechanical properties," The American Journal of Physiology-Lung Cellular and Molecular Physiology, vol. 295, no. 6, pp. L1007-L1017, 2008.

[164] E. Tourkina, M. Bonner, J. Oates et al., "Altered monocyte and fibrocyte phenotype and function in scleroderma interstitial lung disease: reversal by caveolin-1 scaffolding domain peptide," Fibrogenesis and Tissue Repair, vol. 4, no. 1, article 15, 2011.

[165] Z. Li, P. J. Wermuth, B. S. Benn, M. P. Lisanti, and S. A. Jimenez, "Caveolin-1 deficiency induces spontaneous endothelial-tomesenchymal transition in murine pulmonary endothelial cells in vitro," The American Journal of Pathology, vol. 182, no. 2, pp. 325-331, 2013.

[166] S. A. Jiménez, S. V. Castro, and S. Piera-Velázquez, "Role of growth factors in the pathogenesis of tissue fibrosis in systemic sclerosis," Current Rheumatology Reviews, vol. 6, no. 4, pp. 283294, 2010.

[167] M. Trojanowska, "Role of PDGF in fibrotic diseases and systemic sclerosis," Rheumatology, vol. 47, supplement, pp. v2v4, 2008.

[168] M. Bielecki, K. Kowal, A. Lapinska, S. Chwiesko-Minarowska, L. Chyczewski, and O. Kowal-Bielecka, "Peripheral blood mononuclear cells from patients with systemic sclerosis spontaneously secrete increased amounts of vascular endothelial growth factor (VEGF) already in the early stage of the disease," Advances in Medical Sciences, vol. 56, no. 2, pp. 255-263, 2011. 
[169] P. M. Krein and B. W. Winston, "Roles for insulin-like growth factor I and transforming growth factor- $\beta$ in fibrotic lung disease," Chest, vol. 122, no. 6, supplement, pp. 289S-293S, 2002.

[170] B. Widyantoro, N. Emoto, K. Nakayama et al., "Endothelial cell-derived endothelin-1 promotes cardiac fibrosis in diabetic hearts through stimulation of endothelial-to-mesenchymal transition," Circulation, vol. 121, no. 22, pp. 2407-2418, 2010.

[171] G. R. Grotendorst, "Connective tissue growth factor: a mediator of TGf- $\beta$ action on fibroblasts," Cytokine and Growth Factor Reviews, vol. 8, no. 3, pp. 171-179, 1997.

[172] A. Leask and D. J. Abraham, "The role of connective tissue growth factor, a multifunctional matricellular protein, in fibroblast biology," Biochemistry and Cell Biology, vol. 81, no. 6, pp. 355-363, 2003.

[173] A. Leask and D. J. Abraham, "All in the CCN family: essential matricellular signaling modulators emerge from the bunker," Journal of Cell Science, vol. 119, no. 23, pp. 4803-4810, 2006.

[174] X. Shi-Wen, A. Leask, and D. Abraham, "Regulation and function of connective tissue growth factor/CCN2 in tissue repair, scarring and fibrosis," Cytokine and Growth Factor Reviews, vol. 19, no. 2, pp. 133-144, 2008.

[175] A. Leask, C. P. Denton, and D. J. Abraham, "Insights into the molecular mechanism of chronic fibrosis: the role of connective tissue growth factor in scleroderma," Journal of Investigative Dermatology, vol. 122, no. 1, pp. 1-6, 2004.

[176] C. P. Denton and D. J. Abraham, "Transforming growth factor$\beta$ and connective tissue growth factor: key cytokines in scleroderma pathogenesis," Current Opinion in Rheumatology, vol. 13, no. 6, pp. 505-511, 2001.

[177] A. Igarashi, K. Nashiro, K. Kikuchi et al., "Significant correlation between connective tissue growth factor gene expression and skin sclerosis in tissue sections from patients with systemic sclerosis," Journal of Investigative Dermatology, vol. 105, no. 2, pp. 280-284, 1995.

[178] S. Serratì, A. Chillà, A. Laurenzana et al., "Systemic sclerosis endothelial cells recruit and activate dermal fibroblasts by induction of a connective tissue growth factor (CCN2)/transforming growth factor $\beta$-dependent mesenchymal-to-mesenchymal transition," Arthritis and Rheumatism, vol. 65, no. 1, pp. 258-269, 2013.

[179] S. W. Lee, J. Y. Won, W. J. Kim et al., "Snail as a potential target molecule in cardiac fibrosis: paracrine action of endothelial cells on fibroblasts through Snail and CTGF axis," Molecular Therapy, 2013.

[180] D. P. Bartel, "MicroRNAs: genomics, biogenesis, mechanism, and function," Cell, vol. 116, no. 2, pp. 281-297, 2004.

[181] X. Liu, K. Fortin, and Z. Mourelatos, "MicroRNAs: biogenesis and molecular functions," Brain Pathology, vol. 18, no. 1, pp. 113121, 2008.

[182] T. Treiber, N. Treiber, and G. Meister, "Regulation of microRNA biogenesis and function," Thrombosis and Haemostasis, vol. 107, no. 4, pp. 605-610, 2012.

[183] I. G. Cannell, Y. W. Kong, and M. Bushell, "How do microRNAs regulate gene expression?" Biochemical Society Transactions, vol. 36, no. 6, pp. 1224-1231, 2008.

[184] A. Eulalio, E. Huntzinger, and E. Izaurralde, "Getting to the root of miRNA-mediated gene silencing," Cell, vol. 132, no. 1, pp. 914, 2008.

[185] M. R. Fabian, N. Sonenberg, and W. Filipowicz, "Regulation of mRNA translation and stability by microRNAs," Annual Review of Biochemistry, vol. 79, pp. 351-379, 2010.
[186] M. V. Iorio and C. M. Croce, "MicroRNA dysregulation in cancer: diagnostics, monitoring and therapeutics. A comprehensive review," EMBO Molecular Medicine, vol. 4, no. 3, pp. 143-159, 2012.

[187] X. Jiang, E. Tsitsiou, S. E. Herrick, and M. A. Lindsay, "MicroRNAs and the regulation of fibrosis," FEBS Journal, vol. 277, no. 9, pp. 2015-2021, 2010.

[188] S. Vettori, S. Gay, and O. Distler, "Role of MicroRNAs in fibrosis," Open Rheumatology Journal, vol. 6, pp. 130-139, 2012.

[189] V. Patel and L. Noureddine, "MicroRNAs and fibrosis," Current Opinion in Nephrology and Hypertension, vol. 21, no. 4, pp. 410416, 2012.

[190] T. Bowen, R. H. Jenkins, and D. J. Fraser, "MicroRNAs, transforming growth factor $\beta-1$, and tissue fibrosis," Journal of Pathology, vol. 229, no. 2, pp. 274-285, 2013.

[191] B. Maurer, J. Stanczyk, A. Jüngel et al., "MicroRNA-29, a key regulator of collagen expression in systemic sclerosis," Arthritis and Rheumatism, vol. 62, no. 6, pp. 1733-1743, 2010.

[192] H. Zhu, Y. Li, S. Qu et al., "MicroRNA expression abnormalities in limited cutaneous scleroderma and diffuse cutaneous scleroderma," Journal of Clinical Immunology, vol. 32, no. 3, pp. 514$522,2012$.

[193] N. Honda, M. Jinnin, I. Kajihara et al., “TGF- $\beta$-mediated downregulation of microRNA-196a contributes to the constitutive upregulated type I collagen expression in scleroderma dermal fibroblasts," Journal of Immunology, vol. 188, no. 7, pp. 3323-3331, 2012.

[194] T. Sing, M. Jinnin, K. Yamane et al., "microRNA-92a expression in the sera and dermal fibroblasts increases in patients with scleroderma," Rheumatology, vol. 51, no. 9, pp. 1550-1556, 2012.

[195] W. J. Peng, J. H. Tao, B. Mei et al., "MicroRNA-29: a potential therapeutic target for systemic sclerosis," Expert Opinion on Therapeutic Targets, vol. 16, no. 9, pp. 875-879, 2012.

[196] N. Honda, M. Jinnin, T. Kira-Etoh et al., "miR-150 downregulation contributes to the constitutive type I collagen overexpression in scleroderma dermal fibroblasts via the induction of integrin $\beta 3$," The American Journal of Pathology, vol. 182, no. 1, pp. 206-216, 2013.

[197] K. Makino, M. Jinnin, J. Aoi et al., "Discoidin domain receptor 2-microRNA 196a-mediated negative feedback against excess type I collagen expression is impaired in scleroderma dermal fibroblasts," Journal of Investigative Dermatology, vol. 133, pp. 110-119, 2013.

[198] J. Martin, R. H. Jenkins, R. Bennagi et al., "Post-transcriptional regulation of transforming growth factor $\beta$-1 by microRNA744," PLoS ONE, vol. 6, no. 10, Article ID e25044, 2011.

[199] J. P. Hong, X. M. Li, M. X. Li, and F. L. Zheng, "VEGF suppresses epithelial-mesenchymal transition by inhibiting the expression of Smad3 and miR-192, a Smad3-dependent microRNA," International Journal of Molecular Medicine, vol. 31, no. 6, pp. 14361442, 2013.

[200] R. Kumarswamy, I. Volkmann, V. Jazbutyte, S. Dangwal, D. Park, and T. Thum, "Transforming growth factor- $\beta$-induced endothelial-to-mesenchymal transition is partly mediated by MicroRNA-21," Arteriosclerosis, Thrombosis, and Vascular Biology, vol. 32, no. 2, pp. 361-369, 2012.

[201] B. Hu and S. H. Phan, "Myofibroblasts," Current Opinion in Rheumatology, vol. 25, no. 1, pp. 71-77, 2013.

[202] B. Hinz, S. H. Phan, V. J. Thannickal et al., "Recent developments in myofibroblast biology: paradigms for connective tissue remodeling," The American Journal of Pathology, vol. 180, no. 4, pp. 1340-1355, 2012. 
[203] M. A. Watsky, K. T. Weber, Y. Sun, and A. Postlethwaite, "New insights into the mechanism of fibroblast to myofibroblast transformation and associated pathologies," International Review of Cell and Molecular Biology, vol. 282, pp. 165-192, 2010.

[204] A. J. Gilbane, C. P. Denton, and A. M. Holmes, "Scleroderma pathogenesis: a pivotal role for fibroblasts as effector cells," Arthritis Research and Therapy, vol. 15, no. 3, article 215, 2013.

[205] J. Wei, S. Bhattacharyya, W. G. Tourtellotte, and J. Varga, "Fibrosis in systemic sclerosis: emerging concepts and implications for targeted therapy," Autoimmunity Reviews, vol. 10, no. 5, pp. 267275, 2011.

[206] A. Leask, "Towards an anti-fibrotic therapy for scleroderma: targeting myofibroblast differentiation and recruitment," Fibrogenesis and Tissue Repair, vol. 3, no. 1, article 8, 2010.

[207] A. E. Postlethwaite, H. Shigemitsu, and S. Kanangat, "Cellular origins of fibroblasts: possible implications for organ fibrosis in systemic sclerosis," Current Opinion in Rheumatology, vol. 16, no. 6, pp. 733-738, 2004.

[208] M. Manetti, S. Guiducci, and M. Matucci-Cerinic, “The origin of the myofibroblast in fibroproliferative vasculopathy: does the endothelial cell steer the pathophysiology of systemic sclerosis?" Arthritis and Rheumatism, vol. 63, no. 8, pp. 21642167, 2011. 


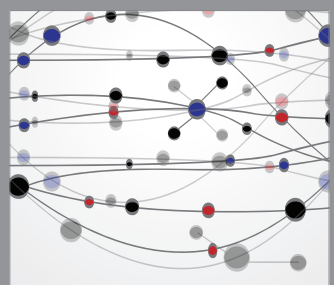

The Scientific World Journal


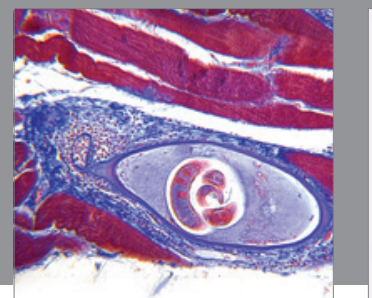

Gastroenterology

Research and Practice
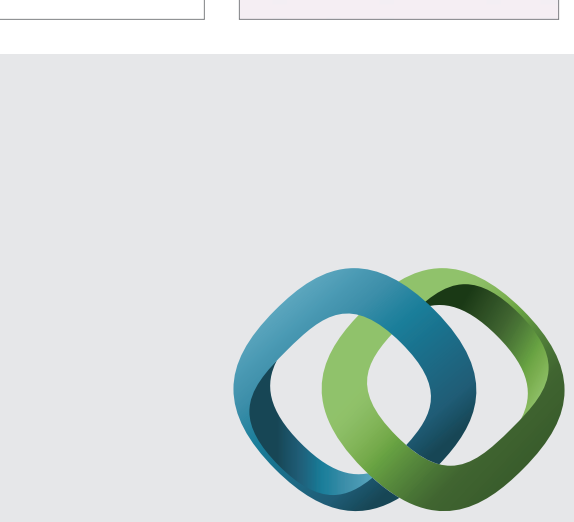

\section{Hindawi}

Submit your manuscripts at

http://www.hindawi.com
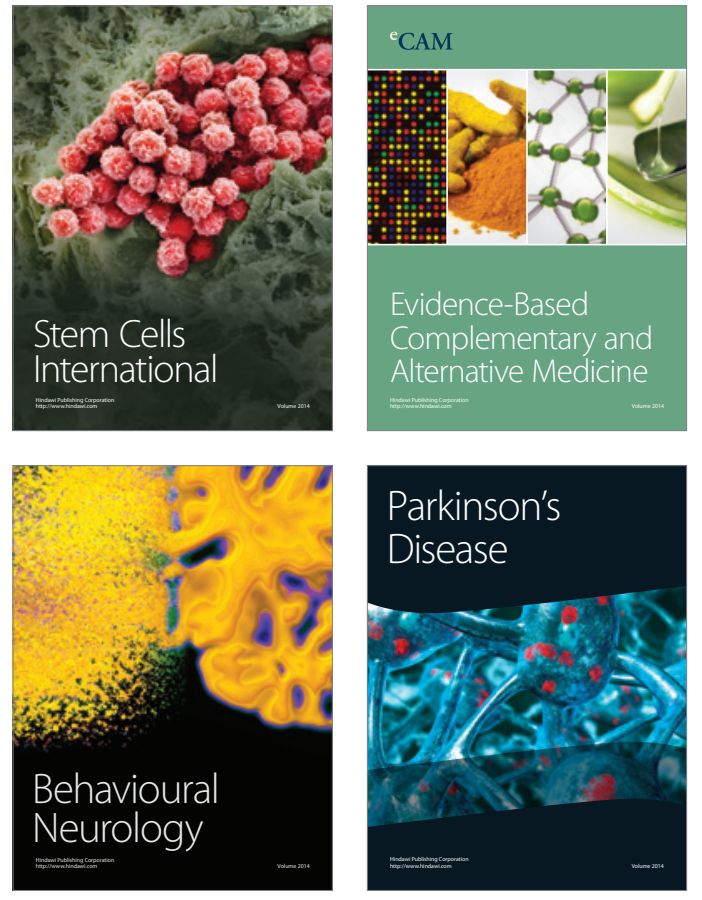


Disease Markers
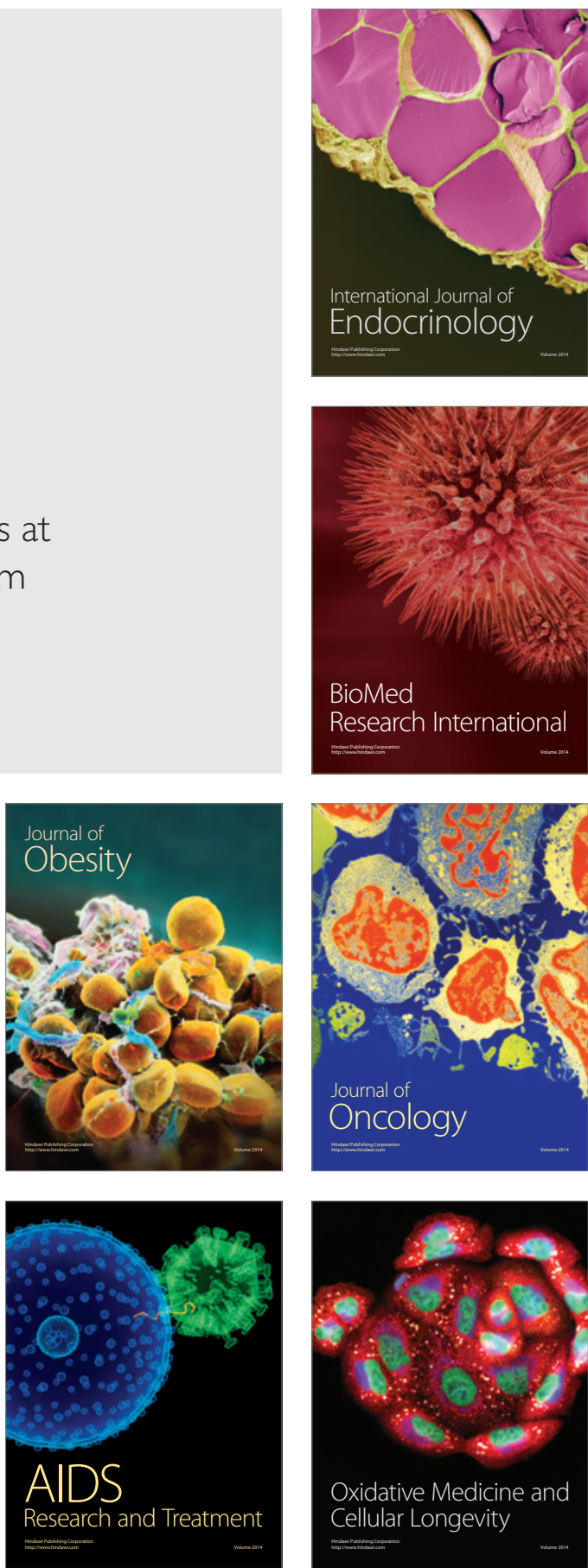